\title{
Intrauterine Contraceptive Device Migration Presenting as Abdominal Wall Swelling: A Case Report
}

\author{
Imtiaz Wani, ${ }^{1}$ Adil Syed, ${ }^{2}$ Muddasir Maqbool, ${ }^{2}$ Iftikhar Bakshi, ${ }^{1}$ Hilal Bhat, ${ }^{1}$ \\ Faheem U1 Hassan Andrabi, ${ }^{1}$ and Naveed Mohsin ${ }^{3}$
}

${ }^{1}$ Department of General Surgery, SKIMS, Srinagar, Kashmir, India

${ }^{2}$ Department of Surgery, SMHS Hospital, Srinagar, Kashmir, India

${ }^{3}$ Department of General Medicine, SKIMS, Srinagar, Kashmir, India

Correspondence should be addressed to Imtiaz Wani, imtazwani@gmail.com

Received 9 July 2011; Accepted 10 August 2011

Academic Editors: A. Anselmi, C. Foroulis, and C. Y. Long

Copyright (c) 2011 Imtiaz Wani et al. This is an open access article distributed under the Creative Commons Attribution License, which permits unrestricted use, distribution, and reproduction in any medium, provided the original work is properly cited.

\begin{abstract}
A number of complications are reported with the use of intrauterine contraceptive devices. These may pursue asymptomatic course or present as an acute abdomen after migration into peritoneal cavity. The authors here are reporting an abdominal wall swelling caused by transuterine migration of a copper intrauterine contraceptive device in a 28 -year-old female. An open approach was used, and impacted foreign body was retrieved.
\end{abstract}

\section{Introduction}

Intrauterine contraceptive devices (IUCD) are regarded as a safe, effective, and economic form of contraception. Possible serious complication associated with its use restricts utilization by a large part of general population [1]. These may migrate inside peritoneal cavity, and pathway for migration is via uterus or fallopian tube. Depending on site and severity of involvement, migration of IUCD present with varying abdominal symptoms and signs or may remain asymptomatic [2]. Radiological investigations can detect asymptomatic migrated IUCD. Even if asymptomatic migrated IUCDs are to be retrieved to prevent serious complications. Retrieval of migrated IUCD may involve open or laparoscopic approach depending on expertise, facilities, and nature of migration.

\section{Case History}

A 28-year-old female presented with progressive swelling of left paraumbilical region of four-month duration. There was a mild aching pain for last two years for which she used to take medications and get relief. Patient had second full-term normal delivery seven months back, six years after her first delivery.
On retrospective questioning, the patient gave history of having used copper- $\mathrm{T}$ as a contraceptive device three years after her first delivery and conceived last delivery with intrauterine device in situ, because of refusal for medical termination of pregnancy in view of religious inhibitions. Neither per speculum examination nor serial pelvic sonography could detect intrauterine contraceptive device during her second pregnancy and was presumed to be expelled without her knowledge as per physician. General physical and systemic examination was normal. Local examination revealed a nontender, firm, mobile $7 \times$ $3.2 \times 1.6$ centimeter swelling fixed to underlying muscle with free overlying skin. Ultrasonography of abdomen showed marked anterior abdominal wall thickening with IUCD-like structure in it. Chronic inflammatory cells were present on fine needle aspiration of swelling. Computed tomography scan of abdomen showed thickening of anterior abdominal wall with thickened underlying abdominal viscera, and a hyperdense structure impacted in underlying abdominal structures encroaching abdominal wall suggestive of IUCDlike structure was seen (Figure 1).

The presence of ectopic IUCD was likely to have generated chronic inflammation only in its immediate surroundings, and tight intraabdominal adhesions preventing 


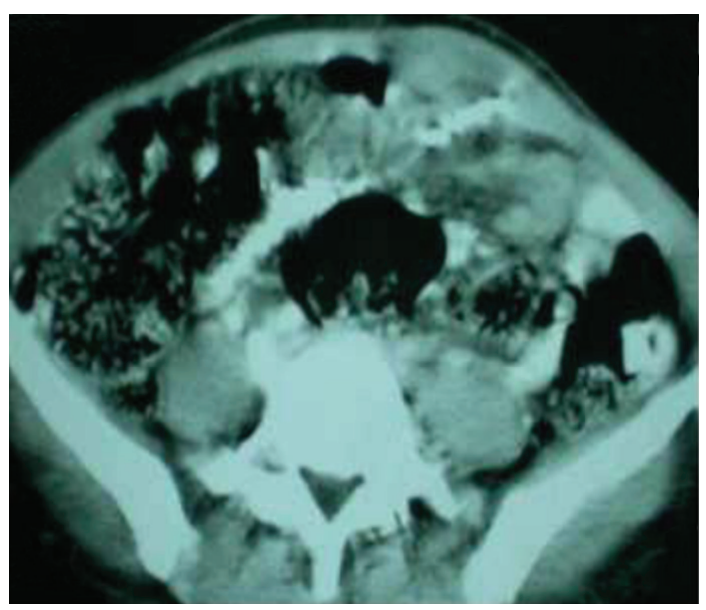

FIGURE 1: CT scan abdomen showing impacted IUCD.

the laparoscopic approach. Laparotomy was done, and IUCD logged in rectus muscle wrapped with omentum from site of perforating uterine wall was seen (Figures 2(a), 2(b), and $2(\mathrm{c}))$. The device was removed along with wrapped omentum with the repair of tissues done. Postoperative period was uneventful. Patient is regularly attending our follow-up clinics.

\section{Discussion}

In developing countries, intrauterine contraceptive device forms one of the integral parts of family planning methods. These are considered as one of the cost-effective contraceptive devices. A range of intrauterine contraceptive devices are offered for measures of contraception. Various copper contraceptive commonly in use are copper T 200, copper T, multiload copper-250, and multiload copper375. The design, copper content, method of placement, and timing of insertion determine profile of side effects. Risk factors for migration are use in nullipara, postpartum or postabortion insertion, faulty technique of insertion, and irregular followup [3]. Migration is associated with a significantly higher rate in immediate postpartum insertion of intrauterine device. Migration can be incomplete or complete. In former type, the device remains attached to the myometrium whereas, in complete migration, the device may be situated in any site in abdomen. Pelvic complications reported with the use of intrauterine contraceptive device are in the form of dysmenorrhea, pelvic inflammatory disease, septic abortion, and hydrosalpinx. Perforation of the uterine wall and transuterine migration of intrauterine contraceptive device into abdominal cavity are rare and can lead to dreadful complications [4]. Perforation of uterus occurs in $1 / 350$ to $1 / 2500$ insertions [5]. Inert positioning, fragility of uterine wall due to recent birth, abortion, and pregnancy are contributory to the possibility of uterine perforation [6]. After perforating uterine wall intrauterine contraceptive device can have migration to colon, wall of iliac vein, bladder, appendix, omentum, perirectal fat,

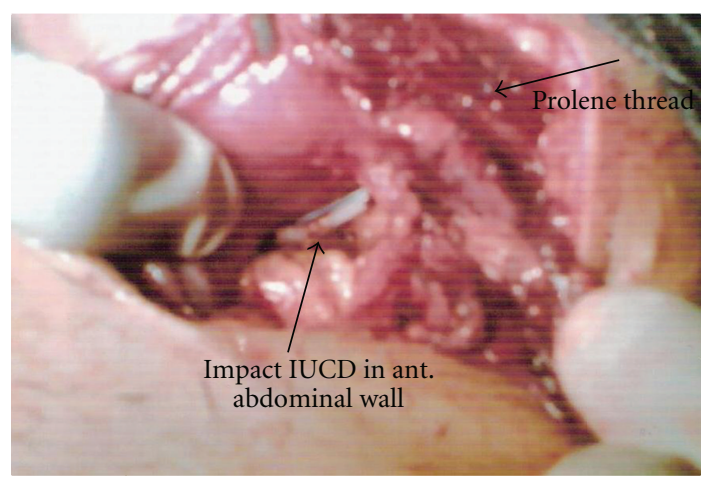

(a)

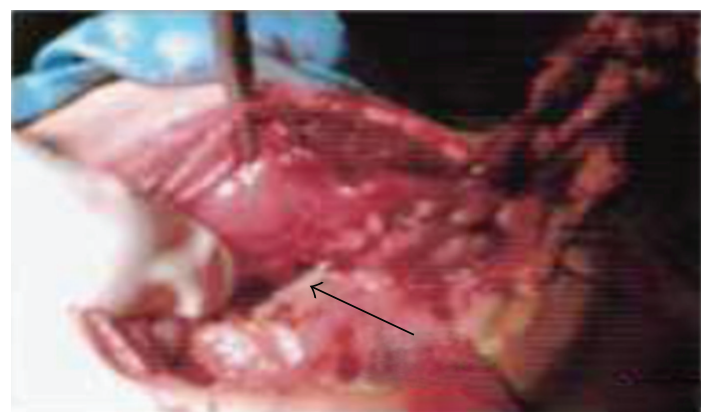

(b)

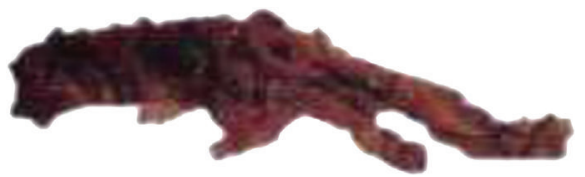

(c)

Figure 2: (a) and (b) Intraoperative figure showing impacted IUCD. (c) Showing retrieved IUCD.

retroperitoneal space, pouch of douglas, and ovaries [710]. Rarely, IUCD migrated can be located in lower anterior abdominal wall [11]. In bladder, they lead to calculi formation [12]. Regular self-examination, investigation of persistent pain, or disappearance of strings may detect migration early [13]. X-ray abdomen, ultrasonography, and computed tomography scan are usually used for diagnosis. Plain X-ray is useful and can detect migration of intrauterine contraceptive device. Ultrasonography and computed tomography scan are adjuncts in locating site of impaction. Transvaginal ultrasonography visualizes the IUD located outside the uterus. There are proponents of leaving migrated asymptomatic intrauterine contraceptive device as such, but not well supported in literature. All the copper-containing devices require laparotomy for removal because of an omental or peritoneal reaction incited with their presence [14]. Detection of asymptomatic migrated intrauterine contraceptive device necessitates retrieval in order to discourage psychosomatic symptomatology, commonly associated with forgotten devices and prevention of future grave complications [15]. Laparotomy, colpotomy, and laparoscopy are treatment options available for migrated foreign bodies. Laparoscopy has advantage that it enables 
localization of the intrauterine contraceptive device and full lesion assessment [16]. Parietoepiploic adhesions and IUCD impacted in gut wall limit generous use of laparoscopy in salvage.

\section{Conclusion}

A regular followup for detection of misplacing of intrauterine device is stressed as it can have unusual presentation. Migration to anterior abdominal wall presenting as swelling could be considered as differential diagnosis of abdominal swelling.

\section{Consent}

Patient described in the paper has given their informed consent for the case report to be published.

\section{Conflict of Interests}

The authors declare that there is no conflict of interests.

\section{References}

[1] A. Tinelli, R. Tinelli, A. Malvasi, C. Cavallotti, and F. G. Tinelli, "The intrauterine device in modern contraception: still an actuality?" European Journal of Contraception and Reproductive Health Care, vol. 11, no. 3, pp. 197-201, 2006.

[2] H. R. Koo, Y. T. Oh, Y. T. Kim, S. W. Kim, J. H. Kang, and K. W. Kim, "Intrauterine device found in an ovarian carcinoma," Journal of Computer Assisted Tomography, vol. 32, no. 1, pp. 69-71, 2008.

[3] Y. A. Tunçay, E. Tunçay, K. Güzin, D. Öztürk, C. Omurcan, and N. Yücel, "Transuterine migration as a complication of intrauterine contraceptive devices: six case reports," European Journal of Contraception and Reproductive Health Care, vol. 9, no. 3, pp. 194-200, 2004.

[4] A. Joual, B. Querfani, A. Taha et al., "Intravesical migration of an intrauterine contraceptive device complicated by stones," Progres en Urologie, vol. 14, no. 3, pp. 374-375, 2004.

[5] E. Ohana, E. Sheiner, E. Leron, and M. Mazor, "Appendix perforation by an intrauterine contraceptive device," European Journal of Obstetrics Gynecology and Reproductive Biology, vol. 88, no. 2, pp. 129-131, 2000.

[6] E. Junceda Avello, L. Gonzalez Torga, J. Lasheras Villanueva, and G. B. De Quiros A, "Uterine perforation and vesical migration of an intrauterine device. Case observation," Acta Ginecologica, vol. 30, no. 2, pp. 79-86, 1977.

[7] B. Kassab and P. Audra, "The migrating intrauterine device. Case report and review of the literature," Contraception, Fertilite, Sexualite, vol. 27, no. 10, pp. 696-700, 1999.

[8] P. Sarkar, "Translocation of a Copper 7 intra-uterine contraceptive device with subsequent penetration of the caecun: case report and review," British Journal of Family Planning, vol. 26, no. 3, p. 161, 2000.

[9] P. D. Silva and K. M. Larson, "Laparoscopic removal of a perforated intrauterine device from the perirectal fat," Journal of the Society of Laparoendoscopic Surgeons, vol. 4, no. 2, pp. 159-162, 2000.
[10] K. K. Roy, N. Banerjee, and A. Sinha, "Laparoscopic removal of translocated retroperitoneal IUD," International Journal of Gynecology and Obstetrics, vol. 71, no. 3, pp. 241-243, 2000.

[11] B. Mülayim, S. Mülayim, and N. Y. Celik, "A lost intrauterine device. Guess where we found it and how it happened?" European Journal of Contraception and Reproductive Health Care, vol. 11, no. 1, pp. 47-49, 2006.

[12] D. Demirci, O. Ekmekçioğlu, A. Demirtaş, and I. Gülmez, "Big bladder stones around an intravesical migrated intrauterine device," International urology and nephrology, vol. 35, no. 4, pp. 495-496, 2003.

[13] A. Moulay and M. Zahi, "Abdominal migration of intrauterine devices. A report of four cases removed by laparoscopy," Revue Francaise de Gynecologie et d'Obstetrique, vol. 78, no. 3, pp. 163-169, 1983.

[14] J. L. Osborne and M. J. Bennett, "Removal of intra-abdominal intrauterine contraceptive devices," British Journal of Obstetrics and Gynaecology, vol. 85, no. 11, pp. 868-871, 1978.

[15] E. O. Otolorin, "Management of the lost IUD," African Journal of Medicine and Medical Sciences, vol. 14, no. 3-4, pp. 125-129, 1985.

[16] M. Ferchiou, F. Zhioua, M. Hasnaoui, S. Sghaier, A. Jedoui, and S. Meriah, "Laparoscopic surgery of an intraperitoneal intrauterine device," Revue Française de Gynécologie et d'Obstétrique, vol. 90, no. 10, pp. 409-411, 1995. 


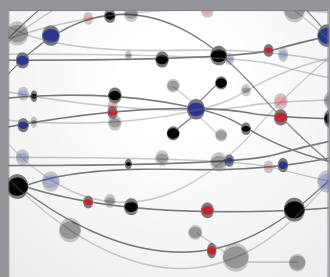

The Scientific World Journal
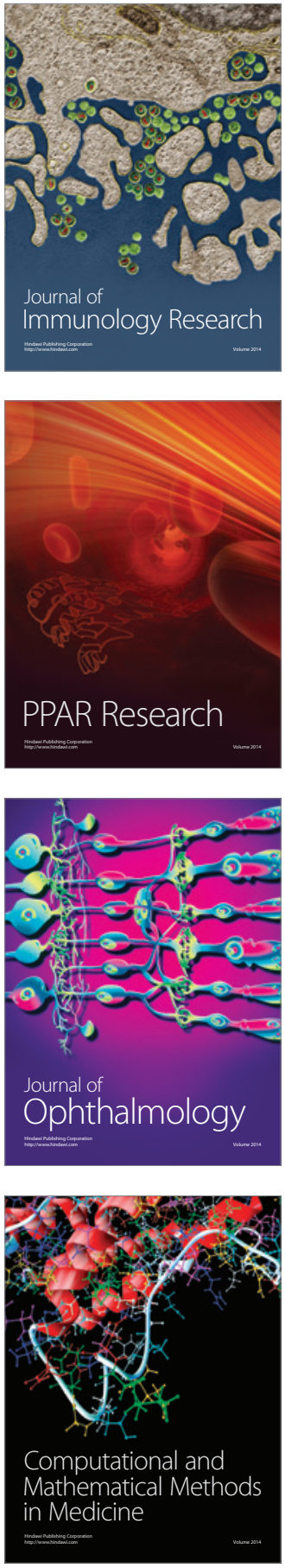

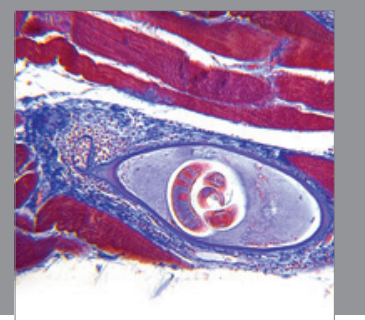

Gastroenterology

Research and Practice
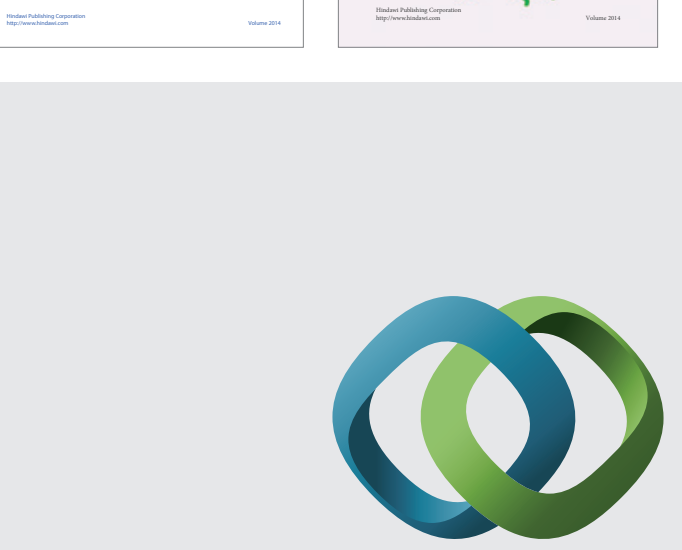

\section{Hindawi}

Submit your manuscripts at

http://www.hindawi.com
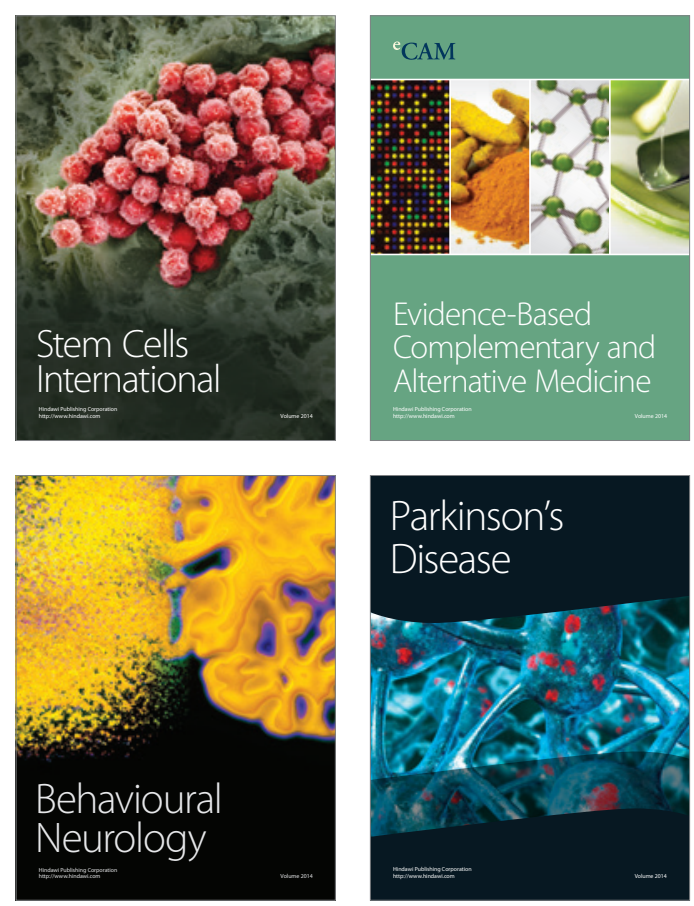

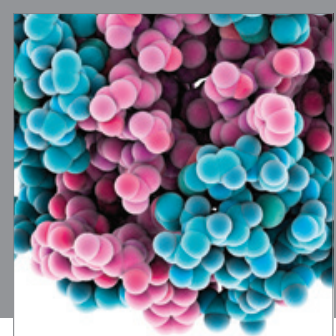

Journal of
Diabetes Research

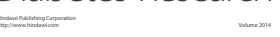

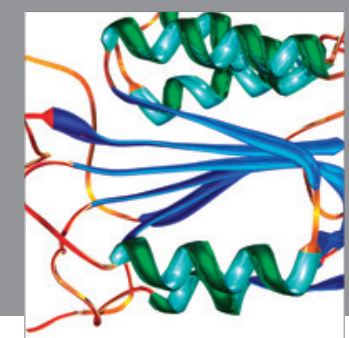

Disease Markers
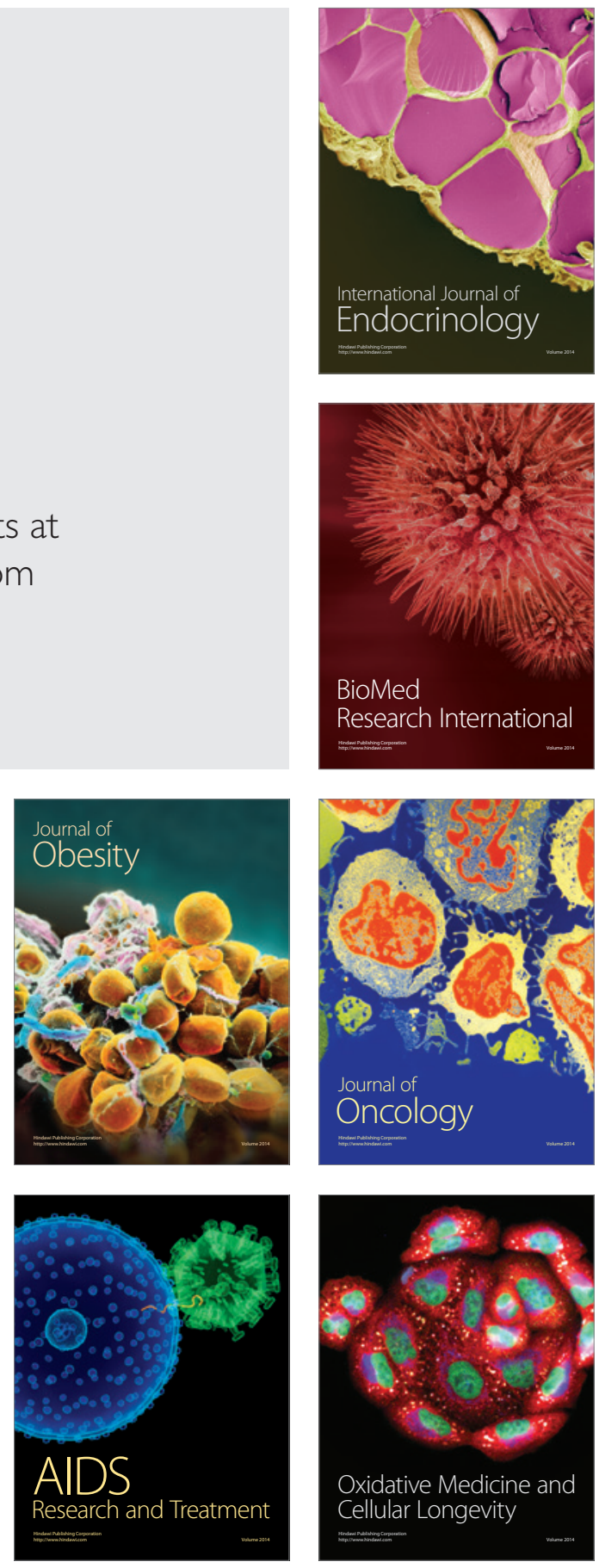